\title{
ADSORPTION BEHAVIOUR OF DEXTRIN ONTO ACTIVATED OYSTER SHELL
}

\author{
C. I. O. Kamalu ${ }^{1}$, P. Oghome ${ }^{2}$, K. N. Nwaigwe ${ }^{3}$, E. E. Anyanwu ${ }^{4}$ \\ ${ }^{I}$ School of Engineering and Engineering Technology, Federal University of Technology, P. M. B. 1526, Owerri, \\ Nigeria \\ ${ }^{2}$ School of Engineering and Engineering Technology, Federal University of Technology, P. M. B. 1526, Owerri, \\ Nigeria \\ ${ }^{3}$ School of Engineering and Engineering Technology, Federal University of Technology, P. M. B. 1526, Owerri, \\ Nigeria \\ ${ }^{4}$ School of Engineering and Engineering Technology, Federal University of Technology, P. M. B. 1526, Owerri, \\ Nigeria
}

\begin{abstract}
The effect of initial dextrin concentration, contact time, $\mathrm{pH}$, temperature and added calcium ion on the adsorption behaviour of dextrin onto oyster shell is investigated. The results obtained show that increase in concentration and temperature below the boiling point of dextrin enhances the adsorption process. It was found in this study that adsorption density varies with $p H$ and is maximum within the range of 2 to 7. The plot of amount of dextrin adsorbed against the concentration of the adsorbate was hyperbolic which conforms to Legmir isotherm. The free energy of dextrin oyster shell adsorption system was found to be $13.23 \mathrm{~kg} / \mathrm{mol}$ and the specific area of the oyster shell for this work was $70.8 \mathrm{~m}^{2} / \mathrm{g}$.
\end{abstract}

Keywords: Adsorption, dextrin, oyster shell, behaviour, crushing, drying $* * *$

\section{INTRODUCTION}

Many adsorbents such as silica get, activated alumina, carbons, and zeolites have been found useful for different adsorbates in different separation technique (Wei, 1994). When molecules moved from a bulk fluid to an adsorbed phase, they lose degrees of freedom and the free energy is reduced. Adsorption in always accompanies by the liberation heat and for physical adsorption, the amount of heat is similar in magnitude normally associated with a chemical reaction (Charles, 1991)

A number of investigators (Subramanian et al, 1988: Caesar, 1968, Weber, 2002) have studied the depression behaviour of starch and its derivatives in the flot6ation of hematite and quarts. Electrostatic interaction and hydrogen bonding have been suggested as a mechanism for the adsorption of polyelectrolytes by Miller et al 1983. according to clap et al, 1998 starch adsorption occurs via hydrogen bonding between the solid surface and the hydroxyl groups on the polymer. Their result showed that common starch in negatively charged in aqueous solution in the $\mathrm{pH}$ range of 3 to 11. The amount of dextrin adsorbed on quartz, however is clearly considerably than that on molybddenite. It was suggested that the adsorption process may be due to hydrophobic bonding with the polymer molecule displacing water molecules at the interface (Liu et al, 1989; Onuoha, 1995). Experimental evidence has shown that the external addition of metal ion enhances adsorption of starch. In the case of dextrin adsorption, the hydrophobic theory lies heavily on the fact that the minerals that adsorbs dextrin are hydrophobic which could be either anisotropic (tale and molybdenite) or heterogeneous (Hals, 1974).
Dextrin dissolves in water to form a sticky solution. It is chiefly used in mixing glues, adhesives on postage stamps ad sticky paper for Steffen textiles to produce a "head" on beer and other carbonated beverages (Hals, 1974). Oyster is on edible bivalve mollusk (one with a two pieced shell). The two parts of an oyster shell are different in size and shape for example Pearl and Bermuda oysters (Gregg el al, 1982) Oysters live attached to occen bottom in hard-surface areas called oysters beds and are found in all temperature and tropical oceans. The three genera of oyster shells (pyenodonta, crassotrea, ostrea) are returned to the beds to provide places on which larvae may set. Cultivated oyster shell beds helps in avoiding depletion in the river beds. Crushed oyster shells are fed to chickens. The shells are also burned and slaked to make lime for fertilizer. Crushed oyster shells can be used as adsorbent (Peterson et al, 1991). Oyster shells are composed of carbonaceous materials, when of carbonaceous materials, when heated in absence of air, mush of the substance devolatilizes, leaving behind a prorous structure of carbon that usually, also, contains some hydrogen (Frish et al 1999). This may then be activated by controlled oxidation with steam or carbon dioxide to further open up the pores and increase total surface area. During the heating process, the oyster shell surface is exposed more by the expansion, which occurs. Also, heating reduces the layers together (Subramanian et al 1988; Caesar 1998). There are four ranges of temperatures at which characteristic transformation or changes are produced in a carbonaceous materials (such as oyster shell) when thermally heated (Healy et al 2002; Khasla et al, 2004). The aim of this study is to establish he adsorption mechanism of dextrin using 
oyster shell. also, in investigate the role played by the nature of oyster shell surface on the mechanism of dextrin adsorption as a function of $\mathrm{pH}$, temperature, dextrin concentration, agitation time and presence and absence of calcium ion.

\section{EXPERIMENTAL}

The oyster shell sample used for this study was obtained from Bonny water side in River State. The dextrin is a pharmaceutical grade, and other materials used are cone. Sulphuric acid, P-nitro phenol, phenol, dil hydrochloric acid, dil sodium hydroxide, calcium sulphate and distilled water. The equipment made use of include $\mathrm{pH}$ meter, mechanical sieve, a shaker, glass electrode, thermometer, spectrophometer, hot place, weighing balance and electric furnace etc.

\subsection{Preparation of thermally Activated Oyster Shell}

\section{and Determination of its specific surface Area.}

The oyster shell sample was size-reduced by crushing, grinding and screening. A weighed sample of $250 \mathrm{~g}$ of the screened by Hall 1974 for 2 hours. The activated oyster shell was cooled in a desicator and stored in a dried and air-tight container to avoid the absorption of moisture. A stock solution of $100 \mathrm{~mol} / \mathrm{L}$ of P-nitro phenol was prepared from eight samples of different concentrations ranging from 10$80 \mathrm{~mol} / \mathrm{L}$. the absorbance of each solution was measured with a $20 \mathrm{uv} /$ visible spectrophotometer at $400 \mathrm{~nm}$. To one gram of oyster shell contain in eight different test tube was added $10 \mathrm{mls}$ of each of the prepared eight concentrations of P-nitro phenol. The test tubes were shaken manually at room temperature and adsorption equilibrium was attached at 25min. after 20mins, the test tubes containing the samples were centrifuged to ensure complete setting of activated oyster shell. The supernatant liquors were decanted and the absorbance of each decanted liquor of P-nitro phenol was then measured on the spectrophotometer at $400 \mathrm{~nm}$. A plot of equilibrium concentration of P-nitro phenol oyster shell versus equilibrium concentration of P-nitro phenol was obtained. The specific surface area is given by the formula

$$
\text { S.S.A }=X_{m} N A
$$

Where $\mathrm{X}_{\mathrm{m}}=$ The monolayer capacity in $\mathrm{mol} / \mathrm{g}$

$\mathrm{N}=$ The Avogado's number

$\mathrm{A}=$ The area of the surface occupied by each solute molecules in $\mathrm{m}^{2}$

\subsection{Preparation of Dextrin Stock solution and}

\section{Determination of concentration of Dextrin Solution.}

Dextrin stock solution was prepared by causticizing since it is a starch derivative, instead of boiling in water or autoclaving. Two grams of dextrin was weighted into a volumetric flask and a $2000 \mathrm{mg} / \mathrm{l}$ stock solution was prepared with distilled water. The suspension was form which was causticized with $2 \%$ potassium hydroxide solution and the mixture was stirred to obtain a homogeneous solution. Dextrin samples of concentrations ranging from 0 to $80 \mathrm{mg} / \mathrm{l}$ were prepared from the stock solution. Two $\mathrm{ml}$ of each of these solution was pipetted into a phenol solution. Then $5 \mathrm{ml}$ of cone. Sulphuric acid was added rapidly making sure that the acid drained directly into the solution without touching the side of the test tubes. An instant brown colour was formed. The tubes were than allowed to stand of $10 \mathrm{mins}$, and was shaken and place in water bath at room temperature for $15 \mathrm{~min}$ before their absorbance were read using a Bauseh and Lomb spectrophotometer at 490nm.

\subsection{Adsorption Experiments}

\subsubsection{Concentration on Adsorption}

One gram activated oyster shall sample crushed to $75 \mu \mathrm{m}$ was pulped using $10 \mathrm{ml}$ of distilled water. The $\mathrm{pH}$ of the pulp was adjusted to 4,7 and 11 respectively. This was followed by the addition of $40 \mathrm{ml}$ of different dextrin solution concentrations to the six-labeled test tubes containing one gram of pulped activated oyster shell. Then the labeled tubes were agitated mechanically at room temperature for $30 \mathrm{mins}$. The mixtures were allowed to stand for 12 hours to ensure complete equilibrium. The oyster shells were then removed by filtration using filter paper. Then, $10 \mathrm{ml}$ of the filtrates were collected and analyzed spectrophotometrically at $490 \mathrm{~nm}$. The amount of dextrin absorbed as dextrin concentration before and after the adsorption reaction was calculated, followed by adsorption density, that is, dextrin adsorbed at equilibrium divided by specific surface area of the oyster shell.

\subsubsection{Contact Time on Adsorption}

One gram of crushed oyster shell of $\mathrm{pH} 7$ was pulped using $10 \mathrm{ml}$ of distilled water in six different test tubes. Then $40 \mathrm{ml}$ of dextrin solution of initial concentration $3000 \mathrm{mg} / \mathrm{L}$ was added into the text tubes. The test tubes were shaken at 10 , $220,30,40,50$ and 60 minutes respectively at room temperature. The samples in the test tubes were filtered and analyzed spectrophotometrically at 490nm.

\subsection{3 pH on Adsorption}

One gram of prepared oyster shell sample crushed to $75 \mathrm{pm}$ was pulped with $10 \mathrm{ml}$ of distilled water. The $\mathrm{pH}$ of the pulp was adjusted to $2,4,6,8,10$ and 11 dextrin solution of concentrations $400 \mathrm{mg} / \mathrm{L}$ and $2000 \mathrm{mg} / \mathrm{L}$ respectively was added into six test tubes. The tubes were agitated for one hour at room temperature and allowed to stand for 12 hours for complete equilibrium. The oyster shell was removed by filtration and $10 \mathrm{ml}$ of the filtrates were collected and analyzed spectrophotometrically at 490nm. The amount of dextrin absorbed as dextrin concentration before and after the adsorption reaction were calculated.

\subsubsection{Temperature on Adsorption}

Forty $\mathrm{ml}$ of dextrin solution of $\mathrm{pH} 7$ and initial concentration $100 \mathrm{mg} / \mathrm{L}$ was equilibrated to the required temperature of $27,30,50$ and $70^{\circ} \mathrm{C}$. One gram of activated 
oyster shell samples crushed to $75 \mu \mathrm{m}$ were added to the solution in six test tubes and shaken for $30 \mathrm{mins}$. Then the tubes were allowed to stand overnight to ensure equilibrium adsorption. The oyster shell was filtered and $10 \mathrm{ml}$ of the filtrate from each tube was analyzed spectrophotometrically at $490 \mathrm{~nm}$.

\subsubsection{Added ion $\left(\mathrm{Ca}^{2+}\right)$ on Adsorption}

One gram of pulped oyster shell was mixed with $\mathrm{CaSO}_{4}$ of initial concentration $100 \mathrm{mg} / \mathrm{L}$ and followed by the addition of $40 \mathrm{ml}$ of different dextrin solution concentration to six different test tubes. The tubes were agitated at room temperature for $30 \mathrm{mins}$. The mixtures were allowed to stand for 12 hours for complete equilibrium. The oyster shell was filtered and $10 \mathrm{ml}$ of the filtrate were collected and analyzed with a spectrophotometer at $190 \mathrm{~nm}$.

\subsubsection{Different Concentration of Added ion $\left(\mathrm{Ca}^{2+}\right)$}

\section{on Adsorption}

One gram of pulped oyster shell wan mixed with different concentration of added ion of the range 0, 50, 100, 200, 250 and $300 \mathrm{mg} / \mathrm{L}$ and to each was added $40 \mathrm{ml}$ of $100 \mathrm{mg} / \mathrm{L}$ of dextrin solution in a test tube. The different test tubes were shaken for $30 \mathrm{mins}$ at room temperature. The mixtures were allowed to stand for 12 hours for complete equilibrium. The oyster shell was removed by filtration and $10 \mathrm{ml}$ of the filtrates were collected to be analyzed with the spectrophotometer at 490nm.

\section{RESULTS}

Below are the results of the various experiments carried out in this work.

Table 1: absorbance for Various Concentration of Paranitrophenol (PNP) solution at 400nm

\begin{tabular}{|l|l|}
\hline $\begin{array}{l}\text { Concentration of PNP } \\
\text { (mol/litre) }\end{array}$ & $\begin{array}{l}\text { Absorbance } \\
\text { at 400nm }\end{array}$ \\
\hline 10 & 0.268 \\
\hline 20 & 0.406 \\
\hline 30 & 0.545 \\
\hline 40 & 0.683 \\
\hline 50 & 0.820 \\
\hline 60 & 0.58 \\
\hline 70 & 1.097 \\
\hline 80 & 1.234 \\
\hline
\end{tabular}

Table 2: Concentration of Dextrin and Absorbance of $490 \mathrm{~nm}$

\begin{tabular}{|l|l|}
\hline $\begin{array}{l}\text { Concentration of PNP } \\
\text { (mol/litre) }\end{array}$ & $\begin{array}{l}\text { Absorbance } \\
\text { at 400nm }\end{array}$ \\
\hline 0 & 0.00 \\
\hline 10 & 0.13 \\
\hline 20 & 0.26 \\
\hline 30 & 0.38 \\
\hline 40 & 0.50 \\
\hline 50 & 0.65 \\
\hline 60 & 0.76 \\
\hline 70 & 0.90 \\
\hline 80 & 1.02 \\
\hline
\end{tabular}

Table 3a: effect of Concentration on Dextrin Adsorption into Oyster Shell (pH7.0)

\begin{tabular}{|l|l|l|l|l|}
\hline $\begin{array}{l}\text { Initial Cone. Of } \\
\text { Dextrin (mg/L) }\end{array}$ & $\begin{array}{l}\text { Absorbance } \\
\text { Equilibrium } \\
\mathbf{4 9 0 n m}\end{array}$ & $\begin{array}{l}\text { Equilibrium } \\
\text { Concentration } \\
\text { (mg/L) }\end{array}$ & $\begin{array}{l}\text { Dextrin Adsorbed } \\
\text { at Equilibrium } \\
\text { Cone. } \mathbf{( m g / L )}\end{array}$ & $\begin{array}{l}\text { Absorption } \\
\text { Density }\left(\mathbf{m g}_{\mathbf{m}} \mathbf{m}^{\mathbf{3}}\right)\end{array}$ \\
\hline 500 & 1.4 & 110 & 390 & 5.51 \\
\hline 1000 & 3.7 & 290 & 710 & 10.03 \\
\hline 2000 & 6.2 & 490 & 1510 & 21.33 \\
\hline 3000 & 8.9 & 700 & 2300 & 32.49 \\
\hline 4000 & 14.3 & 1125 & 2875 & 40.61 \\
\hline 5000 & 24.3 & 1911.2 & 3088 & 43.60 \\
\hline
\end{tabular}

Table 3b: Effect of Concentration on Dextrin Adsorption onto Oyster Shell $(\mathrm{pH} \pm 11)$

\begin{tabular}{|l|l|l|l|l|}
\hline $\begin{array}{l}\text { Initial Cone. Of } \\
\text { Dextrin (mg/L) }\end{array}$ & $\begin{array}{l}\text { Absorbance } \\
\text { Equilibrium } \\
\mathbf{4 9 0 n m}\end{array}$ & $\begin{array}{l}\text { Equilibrium } \\
\text { Concentration } \\
(\mathbf{m g} / \mathbf{L})\end{array}$ & $\begin{array}{l}\text { Dextrin Adsorbed } \\
\text { at } \begin{array}{c}\text { Absorption } \\
\text { Equilibrium }\end{array}\end{array}$ & $\begin{array}{l}\text { Density }(\mathbf{m g} / \mathbf{L}) \\
\text { Cone }\end{array}$ \\
\hline 500 & 0.7 & 50 & 450 & 6.36 \\
\hline 1000 & 1.9 & 150 & 850 & 12.00 \\
\hline 2000 & 3.7 & 290 & 1710 & 24.15 \\
\hline 3000 & 5.2 & 410 & 2590 & 36.58 \\
\hline 4000 & 8.4 & 660 & 3340 & 47.18 \\
\hline 5000 & 11.5 & 904 & 4096 & 57.85 \\
\hline
\end{tabular}


Table 3c: effect of Concentration on Dextrin Adsorption onto Oyster shell ( $\mathrm{pH} 4)$

\begin{tabular}{|l|l|l|l|l|}
\hline $\begin{array}{l}\text { Initial Cone. Of } \\
\text { Dextrin (mg/L) }\end{array}$ & $\begin{array}{l}\text { Absorbance } \\
\text { Equilibrium at 490nm }\end{array}$ & $\begin{array}{l}\text { Equilibrium } \\
\text { Concentration (mg/L) }\end{array}$ & $\begin{array}{l}\text { Dextrin Adsorbed at } \\
\text { Equilibrium Cone. (mg/L) }\end{array}$ & $\begin{array}{l}\text { Absorption } \\
\left.\text { Density (mg/m } \mathbf{m}^{\mathbf{3}}\right)\end{array}$ \\
\hline 500 & 1.3 & 100 & 400 & 5.65 \\
\hline 1000 & 3.0 & 240 & 760 & 10.73 \\
\hline 2000 & 5.3 & 1500 & 21.18 \\
\hline 3000 & 10.6 & 1150 & 2160 & 30.51 \\
\hline 4000 & 14.6 & 1470 & 2850 & 40.25 \\
\hline 5000 & 18.6 & 3530 & 49.90 \\
\hline
\end{tabular}

Table 4: Effect of Agitation Time of Dextrin adsorption onto Oyster Shell (pH 7) Initial concentration 3000mg/l)

\begin{tabular}{|l|l|l|l|l|}
\hline $\begin{array}{l}\text { Time } \\
(\mathbf{m i n} .)\end{array}$ & $\begin{array}{l}\text { Absorbance equilibrium } \\
\text { at (490nm) }\end{array}$ & $\begin{array}{l}\text { Equilibrium } \\
\text { concentration (mg/l) }\end{array}$ & $\begin{array}{l}\text { Dextrin Adsorbed at } \\
\text { Equilibrium (mg/l) }\end{array}$ & $\begin{array}{l}\text { Adsorption Density } \\
\left(\mathbf{m g} / \mathbf{m}^{\mathbf{3}}\right)\end{array}$ \\
\hline 10 & 9.1 & 720 & 2280 & 32.20 \\
\hline 20 & 6.9 & 540 & 2460 & 34.75 \\
\hline 30 & 5.4 & 430 & 2570 & 36.30 \\
\hline 40 & 4.0 & 310 & 2690 & 37.99 \\
\hline 50 & 4.3 & 340 & 2660 & 37.57 \\
\hline 60 & 4.4 & 350 & 2650 & 37.42 \\
\hline
\end{tabular}

Table 5a: Effect of pH on Adsorption of Dextrin onto Oyster Shell (Initial concentration 4000mg/l)

\begin{tabular}{|l|l|l|l|l|}
\hline $\begin{array}{l}\text { Time } \\
(\mathbf{m i n} .)\end{array}$ & $\begin{array}{l}\text { Absorbance equilibrium at } \\
\mathbf{4 9 0 n m )}\end{array}$ & $\begin{array}{l}\text { Equilibrium } \\
\text { concentration (mg/l) }\end{array}$ & $\begin{array}{l}\text { Dextrin Adsorbed } \\
\text { Equilibrium (mg/l) }\end{array}$ & $\begin{array}{l}\text { Adsorption } \\
\left(\mathbf{m g} / \mathbf{m}^{\mathbf{3}}\right)\end{array}$ \\
\hline 2 & 6.4 & 500 & 2500 & \multicolumn{1}{c}{ Density } \\
\hline 4 & 4.2 & 330 & 3670 & 51.44 \\
\hline 6 & 2.0 & 160 & 3840 & 54.24 \\
\hline 8 & 2.5 & 200 & 3800 & 53.67 \\
\hline 10 & 3.0 & 240 & 3760 & 53.11 \\
\hline 11 & 5.8 & 460 & 3540 & 50.00 \\
\hline
\end{tabular}

Table 5b: Effect of pH on Adsorption of Dextrin onto Oyster Shell (Initial concentration = 2000mg/l)

\begin{tabular}{|l|l|l|l|l|}
\hline $\begin{array}{l}\text { Time } \\
(\mathbf{m i n} .)\end{array}$ & $\begin{array}{l}\text { Absorbance } \\
\text { equilibrium at (490nm) }\end{array}$ & $\begin{array}{l}\text { Equilibrium } \\
\text { concentration (mg/l) }\end{array}$ & $\begin{array}{l}\text { Dextrin Adsorbed at } \\
\text { Equilibrium (mg/l) }\end{array}$ & $\begin{array}{l}\text { Adsorption } \\
\left(\mathbf{m g} / \mathbf{m}^{\mathbf{3}}\right)\end{array}$ \\
\hline 2 & 10.7 & 850 & 1150 & 16.24 \\
\hline 4 & 640 & 1360 & 19.21 \\
\hline 6 & 8.1 & 350 & 1650 & 23.31 \\
\hline 8 & 4.4 & 310 & 1690 & 23.87 \\
\hline 10 & 3.9 & 470 & 1530 & 21.61 \\
\hline 11 & 6.0 & 730 & 1270 & 17.94 \\
\hline
\end{tabular}

Table 6: Effect of Temperature on Adsorption Behaviour of Dextrin onto Oyster Shell Sample (pH = 7.0. Initial dextrin

\begin{tabular}{|l|l|l|l|l|}
\hline Temperature "C & $\begin{array}{l}\text { Absorbance } \\
\text { Equilibrium at 490nm }\end{array}$ & $\begin{array}{l}\text { Equilibrium } \\
\text { concentration (gm/l) }\end{array}$ & $\begin{array}{l}\text { Dextrin Adsorbed at } \\
\text { Equilibrium (mg/l) }\end{array}$ & $\begin{array}{l}\text { Adsorption } \\
\text { (mg/m) }\end{array}$ \\
\hline 10 & 1.2 & 90 & 910 & 12.85 \\
\hline 30 & 70 & 930 & 13.13 \\
\hline 50 & 0.9 & 50 & 950 & 13.42 \\
\hline 70 & 0.7 & 20 & 980 & 13.84 \\
\hline
\end{tabular}

Table 7a: Effect of Added ion $\left(\mathrm{Ca}^{2+}\right)$ on adsorption of Dextrin onto Oyster shell (pH-7.0. Initial concentration 1000mg/l)

\begin{tabular}{|l|l|l|l|l|}
\hline $\begin{array}{l}\text { Initial Cone } \\
\text { Dextrin }\end{array}$ & $\begin{array}{l}\text { Absorbance Equilibrium } \\
\text { at 490nm }\end{array}$ & $\begin{array}{l}\text { Equilibrium } \\
\text { concentration (gm/l) }\end{array}$ & $\begin{array}{l}\text { Dextrin Adsorbed at } \\
\text { Equilibrium (mg/l) }\end{array}$ & $\begin{array}{l}\text { Adsorption } \\
\text { (mg/m) }\end{array}$ \\
\hline 500 & 1.0 & 80 & 420 & 5.93 \\
\hline 1000 & 2.0 & 160 & 840 & 11.86 \\
\hline 2000 & 40 & 300 & 1700 & 24.01 \\
\hline 3000 & 7.0 & 520 & 2480 & 35.03 \\
\hline 4000 & 9.0 & 680 & 3320 & 46.89 \\
\hline 5000 & 12.0 & 900 & 4100 & 57.91 \\
\hline
\end{tabular}


Table 7b: Effect of Different concentration of Added ion (CO2+) on Dextrin Adsorption onto Oyster Shell (Initial Concentration of Dextrin 1000mg/l)

\begin{tabular}{|l|l|l|l|l|}
\hline $\begin{array}{l}\text { Initial Cone of } \\
\text { Ca2+ ion (mg/l) }\end{array}$ & $\begin{array}{l}\text { Absorbance Equilibrium } \\
\text { at 490nm }\end{array}$ & $\begin{array}{l}\text { Equilibrium } \\
\text { Concentration }(\mathbf{g m} / \mathbf{l})\end{array}$ & $\begin{array}{l}\text { Dextrin Adsorbed at } \\
\text { Equilibrium (mg/l) }\end{array}$ & $\begin{array}{l}\text { Adsorption Density } \\
(\mathbf{m g} / \mathbf{m})\end{array}$ \\
\hline 0 & 3.8 & 290 & 710 & 10.03 \\
\hline 50 & 0.3 & 220 & 780 & 11.02 \\
\hline 100 & 0.2 & 160 & 840 & 11.86 \\
\hline 200 & 0.4 & 300 & 700 & 9.88 \\
\hline 250 & 0.4 & 450 & 550 & 7.76 \\
\hline 300 & 0.8 & 600 & 400 & 5.65 \\
\hline
\end{tabular}

\section{DISCUSSION}

The adsorption mechanism of organic polymers such as dextrin are considerably more complex than that of simple ions or molecules (Gregg et al, 1982). The actual adsorption of dextrin onto activated oyster shell is thought to be by multiple point attachment, arising from the interaction between the hydroxyl $(\mathrm{OH})$ functional group of dextrin with sites on the shells. The conformation of dextrin on the activated oyster shell is complicated, because it is extremely unlikely that each segment of the dextrin is attached to surface. The polymer chain adsorbs at several points along its length and unabsorbed trains of segment between these points, form loops or bridges extending into the solution. The higher the flexibility of a polymer, the more complicated will be its conformation on the activated oyster shell or into their pores, this is almost the stage that determines the adsorption rate. From Table 1 and 2 shows an increase in absorbance at various concentration of paranitrophenol and dextrin at 400 and $490 \mathrm{~nm}$. The calibration curve of table I gave a linear plot. (figure 1), which obeys the Bear Lanberts law.

The study of various concentrations of dextrin at different $\mathrm{pH}$ (tables 3a-3c) showed that an increase in the concentration of the dextrin (adsorbate), enhances the adsorption density which increase the affinity of adsorbate to be adsorbed at the surface of the oyster shell. The effect of agitation/contact time on adsorption onto oyster shell as shown in Table 4 revealed that an increase in the agitation time of contact, increases the adsorption rate for a time range of 10-40mins and then, an instantancous decrease in adsorption density for a time range of 40-60mins.

The effect of $\mathrm{pH}$ on the adsorption behaviour of dextrin onto oyster shell at initial concentration of 2000 and $400 \mathrm{mg} / \mathrm{l}$ was investigated, and the results in Tables $5 \mathrm{a}$ and $5 \mathrm{~b}$ showed that the adsorption process of dextrin does not depend strongly on $\mathrm{pH}$. However, from the result, it was observed that, an increase in adsorption density occurs from a $\mathrm{pH}$ range of 2-6 and a decrease for $\mathrm{pH}$ range of 6-11. Adsorption of dextrin was favoured by the increase in temperature below the boiling pint of dextrin as shown in Table 6 .

The addition of calcium ion $\left(\mathrm{Ca}^{2+}\right)$ to the dextrin concentration increases the adsorption rate linearly and increases adsorption density for $\mathrm{Ca}^{2+}$ concentration of 0 to $100 \mathrm{mg} / \mathrm{l}$ as well as decreases the adsorption rate for $\mathrm{Ca}^{2+}$ concentration of 100 to $300 \mathrm{mg} / \mathrm{l}$ as displayed in Table $7 \mathrm{a}$ and $7 \mathrm{~b}$ respectively.

A plot of dextrin adsorbed versus initial concentration of dextrin (Table 3) conforms to langmuir isotherm (figure 2). The free energy of dextrin oyster adsorption system was calculated to be $13.23 \mathrm{KJ} / \mathrm{mole}$ by applying Anchnius equation at $28^{\circ} \mathrm{C}$, the operating temperature for this study and the $\mathrm{kc}$ value of $5.05 \times 10^{-03}$ obtained by least square analysis of the equation

$$
\mathrm{C}=\frac{\mathrm{Kc} \mathrm{CmC}}{1+\mathrm{KcC}} \quad \text { (Charles, 1991). }
$$

The specific surface area of the oyster shell used for this study was calculated to be $70 \mathrm{~m}^{2} / \mathrm{g}$.

\section{CONCLUSION}

This study shows that the adsorption of dextrin onto oyster shell is characterized by physical adsorption resulting from hydrophobic bonding. The adsorption process was followed by the Langmuir isotherm. It was observed that increase in temperature facilitate adsorption of dextrin its boiling point. Also, the slight dependence of adsorption process on $\mathrm{pH}$, indicates that electrostatic interaction in not a contributing factor on the adsorption energy.

\section{REFERENCES}

[1] Caesar, G.V. (1968), Dextrins and dextrinization, in starch and its dextrivatives, Radly, J.A. Ed. Chapman and Hall, London. P282.

[2] Charles, N.S (1991). Heterogeneous Catalysis in Industrial Practice $2^{\text {nd }}$ Edition MeGraw-Hill Inc. pp 131-174.

[3] Clap, C.E. and Emerson, W.W. (1998). Reaction between calcium and Montmorrilonite and Polysaccherides Soil Science J. Chem. Vol. 64, pp 210-216

[4] Frish, H.I. Hellmmman, M.Y. and Lundberg, .I. (1999). Adsorption of polymers, Polystyrene on Carbon. J. Polym. Sci. pp 38,441.

[5] Greg. S.J. and Sing, K.S.W. (1982). Adsorption, Surface area, and porosity Academic New York, p 150. 
[6] Hals, O, (1994), Biological treatment and activated carbon adsorption, M.Sc. Thesis, Dept. of Chemical Engineering, Mc. Master University Hamilton, Ontario, p 144.

[7] Healy, T.W. and Lamer, V.K. (2002). The adsorption Flocculation reaction of a Polymer with an aqueous colloidal dispersion. J. Pys. Chem.. Pp 66

[8] Khosla, N.K., Bhaghat, R.P., Grandi, K.S. and Biswas, A.K. (2004) colloidal, Surface J. chem.. Vol. 8.p. 125.

[9] Liu, Q. and Laskowski, J.S. (1989). The role of metal Hydroxide at mineral surfaces in Dextrin Adorption. Studies on modifies Quartz samples, Int. J of Min Process Vol. 20 pp 297-316.

[10] Miller, J.D. Laskkowski, J.S. and Change, S.S. (1983). Dextrin Adsorption by Oxidized Coal. Colloids and surfaces. Vol. 8. pp 137-151.

[11] Onuoha, I.J. (1995). The effect of surface modification on dextrinadsorption onto Haematic. B.Sc. Thesis, Federal University of Technology Owerri Pp 10-13.

[12] Peterson, C. and Kwei, T.K. (1991). The Kineties of Polymer Adsorption onto solid surface, J. of chem.. vol. 65, pp 1330-1333.

[13] Subramanian, S. and Natarajan, K.A. (1988). Some Studies on the adsorption behaviour of an oxidized starch onto Haematite Min-eng. Vol. 1 No. 3 pp 241254.

[14] Weber, W.J. (2002), competitive interacting in adsorption from dilute aqueous biselute systems, J. appl. Chem., Pp 14, 565. 




